\title{
Neonatal Pediatrics at the Century Mark ${ }^{1}$
}

\author{
WILLIAM A. SILVERMAN \\ Greenbrae, California 94904
}

Neonatal pediatrics has made stunning and completely unprecedented progress in recent years. Nonetheless, an increasing number of voices now ask, "Where is this field of medicine going?" Is it, dare one ask, even headed in the right direction? These are reasonable questions, but first we need to know where this subspeciality of pediatrics has been. The current phenomenon is all the more remarkable because it differs so completely from the past.

\section{TWO EPOCHS}

The 100-year saga of American interest and concerted action in neonatal medicine can be divided into two epochs. The first 70 years were, I would say, quiet and farmlike; those years might be thought of as a "pastoral era." The calm ended about 30 years ago. It was replaced by a very active time-a "mechanistic era" that extends to the present day.

At the time of the founding of the American Pediatric Society (APS) in 1888, there was surprisingly little expressed interest in the newborn. For example, the founders voiced concern about the high mortality rates in infancy and childhood (1). But the disproportionate loss of life in the immediate neonatal period was not singled out as a national problem deserving special attention. To some extent the situation was blurred since many of the early neonatal deaths were declared to be stillborn (2). In the 1880 s, a little more than $95 \%$ of American women delivered their infants at home (3); any effort to rescue a nonbreathing or grossly malformed neonate was carried out on the family's turf where the immediate and long-term social consequences of any action by birth attendants were uppermost in the minds of all concerned. Most of the early deaths were seen by families and by doctors as the "expected" reproductive loss-similar in every way to the large number of early deaths in all species. More specifically, it seemed inhumane to prolong the lives of very small or malformed babies. Throughout all the millennia of human existence, the metamorphosis of a newborn from biologic creation to social being and family member took place only if and when nurturing care was provided by parents. One hundred years ago, few parents were willing to place the interests of a newly born child with major biologic imperfections ahead of all others in the family. There was a fairly general, but silent, understanding that the new arrival had only a tentative claim to full rights of membership in a family (4).

Welfare of the social unit also seemed to be the prime concern of the first American doctors with a special interest in the health of children. From the writings of Abraham Jacobi (5), the first President, and other founders of the APS, it appears that medical action was guided by a consideration of the status of the new baby as a potential family member.

\section{ORGANIZED EFFORTS IN FRANCE}

In contrast to American inertia in the late $1880 \mathrm{~s}$, the first systematic programs organized by physicians to reduce neonatal mortality were well under way in France (6). The planned

' Reprinted with permission from Perspectives in Biology and Medicine 32(2) Winter 1989, pp 159-170. (C) 1989 by the University of Chicago. medical action began in Paris and in Nice during the 1870 s, and, interestingly, the move was not started in response to pleas from parents. The concerted effort was, in fact, motivated less by humanitarian or religious interests than by the considerations of economics and war. What was stressed was the need for more rapid growth of population to provide the country with workers and soldiers.

The medical measures were taken in response to the immense loss of life in France from military action and from months of famine during the siege of Paris in the Franco-Prussian War of 1870-1871. The acute decimation of population was particularly alarming to the French because it was accompanied by a declining birthrate. By 1880 , the annual number of infants born in Germany was twice the number born in France. One physician warned that if no change occurred, in 40 years, Germany would be able to field an army that would double the size available for conscription in France.

\section{NEONATES "MEANT" TO LIVE}

The story of the development of incubators and special techniques of care by patriotic French obstetricians has been told many times and I will not repeat it here (8), but I do want to point out the environmentalist assumption that guided the early caretakers, because the initial mindset persisted, with very little change, until about 30 years ago. The argument went something like this: If favorable conditions for survival are provided, those newborn infants who were "meant" to live will do so. As in this country, most of the French deaths occurred at home in the first hours after delivery. Sickly survivors were brought to special facilities for care after the first day or two of life; here expert nurses provided warmth, careful feeding, cleanliness, and attentive care to minimize exertion. The nonspecific supportive measures were set out as standardized routines for the management of what was called "congenital feebleness" (9). The empirical approach-essentially a screening process to identify infants who were "meant to survive" - was more farm-like than medical, but the results were hailed as successful. The simple nursing routines were quite effective in reducing mortality for all but the smallest "weaklings;" those with birth weights below $1 \mathrm{~kg}$, for example, were labeled "previable."

The early diffusion of the French ideas and techniques of care was quite erratic. Many physicians, in this country and abroad, had serious doubts about the advisability of making extraordinary efforts to keep "weaklings" alive.

\section{AMERICAN MISGIVINGS}

The first paper on prematurity ever presented to the APS was that of Thomas Morgan Rotch of Boston. At the fifth meeting in 1893, he described a new design for a closed incubator to be used in the home as well as in the hospital (10). Henry Dwight Chapin, one of the founders of the APS and its twenty-third President, was less than enthusiastic about the device. He reported experience with 40 infants in the Rotch incubator; all died. Chapin used this occasion to express his doubts about medical efforts to keep "weak" babies alive. He pointed out that 
most of the infants came from, and would return to, miserable tenements. As the result of exposure, ignorance, and neglect, the "weaklings" were often moribund on arrival at the hospital.

Chapin's worry was not uncommon. Hospital visitors often remarked on the futility of saving feeble infants. They looked on the efforts as misguided philanthropy-as a perversion of medicine's goals. Although it might be praiseworthy to try to save such newborns, it was argued, the efforts should be condemned as shortsighted. In 1909, a doctor in Boston asked caretakers to recognize that beyond each of the infants there was, very often, a family problem, and ultimately, a community problempoverty, bad housing, bad food, bad habits and associations, and ignorance of the ways and means of making a clean and healthy life on scanty means. (Dr. Richard C. Cabot was one of the first American physicians to recognize the extramural obligations of hospitals. In October 1905, he employed the first fulltime, paid "social service" worker at the Massachusetts General Hospital.)

\section{AMERICAN ACTION}

Despite these disparaging attitudes, organized programs for special care of "weaklings" were established in a number of American cities in the first few decades of this century [most notably at the Chicago Lying-In Hospital by Joseph DeLee, the Sarah Morris Hospital by Julius Hess, and in the Chicago health department by an energetic commissioner named Herman Bundesen $(11,12)]$. The Children's Bureau was the first agency of our national government that was concerned with the welfare of children. It was established (after much opposition) in 1912 (13). The top priority of the bureau was the promotion of birth registration. It took more than 20 years of uphill effort to obtain reasonably accurate national information about births and neonatal deaths.

An action taken by the APS in 1935 at the 47 th annual meeting in Cleveland was one of the first efforts to stimulate research into neonatal problems. Ethel Dunham, the first woman ever admitted to membership in the previously all-male society, was asked to head a committee on neonatal studies (1). Her committee embarked on a number of consciousness-raising projects that included a survey of research studies and a search for agreement on such terms as "live-born," "premature," and "neonatal period." The stirrings in the national society were the beginning of a slowly growing interest in special problems of the newborn infant.

\section{"HANDS-OFF" ATTITUDE}

Direct clinical studies were hampered by the prevailing notion that "weak" newborn infants must be protected from unnecessary handling. Experienced nurses were convinced that these babies were too easily exhausted. In a previously stable "weakling," bouts of apnea, cyanosis, and deterioration of vitality seemed to be triggered by handling during routine procedures (14). The observations led to a dogmatic "hands-off" policy of care and an unquestioning acceptance of the status quo.

An indication of the ostrich-like attitude reflected in the handsoff policy was revealed in the middle 1940s. When pieces of the puzzle of the $\mathrm{Rh}$ system of antigens and the clinical signs of erythroblastosis fetalis were finally put into place, the new insight led to the daring use, in 1946, of an invasive treatment; exchange transfusion (15). I can remember that the procedure was carried out in the operating room, and that postoperative surveillance of the affected babies took place in the side rooms of the pediatric ward, not in newborn nurseries. The exciting conquest of an important neonatal problem created barely a ripple in the placid atmosphere of term nurseries and premature infant stations. It took a number of devastating disasters to shake up the entrenched hands-off attitude.

\section{OXYGEN DISASTER}

The passive "provide-favorable-conditions-for-survival" approach did not begin to crumble until the 1950s. The decisive blow was delivered when it was shown that what appeared to be minor changes in these "favorable conditions" for small neonates were followed by major and completely unexpected consequences. One of the earliest of the so-called slight modifications was the routine use of high concentrations of oxygen (16). It was observed, in small neonates, that high concentrations of oxygen converted periodic breathing to a regular pattern, and, it was hoped, routine use of continuous oxygen would improve survival and reduce the risk of brain damage from unrecognized oxygen lack. The practice quickly became fashionable; no questions surfaced for a full 10 years of what, in retrospect, can only be called dogmatic slumber.

In mid-1951, the American fashion came under a cloud of suspicion in Britain and Australia. Over the next two years, there were fierce arguments about the inconsistent circumstantial evidence linking oxygen treatment with devastating eye damage. Finally, the paralyzing confusion was resolved when a multicenter randomized trial was carried out in 1953-1954; it demonstrated that curtailment of supplemental oxygen reduced the risk of eye damage by two-thirds.

\section{TICKING BOMBS}

The sobering denouement at the end of a 12-year epidemic of blindness marked the end of the age of innocence in neonatal medicine. Over 10000 children had been blinded as a result of what was considered in the 1940 s to be a small change in oxygen$t$ - 'tment policy. The completely unexpected effect of a longtrusted therapeutic agent like oxygen was startling. It was also painfully clear that none of the time-honored routines to provide "favorable conditions for survival" had ever been rigorously tested. What other bombs, we wondered, were ticking away in the quiet nurseries?

It did not take long to find out. A series of controlled trials that examined long-accepted limits of environmental conditions uncovered a fatal flaw in standard recommendations (17). For more than 20 years, caretakers of very small neonates had been trying faithfully to reduce fluctuation, instead of trying to raise the level, of body temperature. In 1956, it was found that this long-ignored detail in the care of hundreds of thousands of babies was not trivial. A surprisingly small reduction in heat loss resulted in a measurable increase in survival.

\section{NEWLY DISCOVERED "SPECIES"}

These humbling experiences served as a powerful reminder of how little we knew about the problems affecting neonatal patients and how superficial that knowledge was. In many ways, it seemed useful to consider the neonate as a just-discovered and poorly understood new "species" of human being. With that admission of ignorance, research activities that examined neonatal and, later, antenatal problems did, in fact, expand remarkably. The number of perinatal publications rose sharply and steeply after 1955; there was intensification of background studies in physiology and biochemistry; and enormous amount of descriptive information was collected concerning the constituent parts of the fetus and newborn down to the smallest subcellular and molecular units; vital functions and specific disorders soon were described in mechanistic terms; and a powerful array of drugs and physical agents were developed to modify physiologic and pathologic processes.

\section{NEONATAL INTENSIVE CARE}

With the arrival of the "mechanistic era," the old favorableconditions outlook was abandoned. It was replaced by a triumphant attitude that recognized no limits to viability. The admit- 
ted, indeed the proud new aim of neonatal pediatrics was to take on the challenge of altering the expected course of any and all biologic circumstances that had heretofore limited survival. The net results were dramatic-some would say, nearly miraculous. There was concrete evidence of a striking increase in survival of the "weaklings" who were abandoned previously as previable or hopelessly malformed. The momentum of this revolution in neonatal and then antenatal medicine has continued to the present day.

Unfortunately, the lessons learned in the oxygen/blindness episode did not protect infants during the exciting "voyage of discovery" that began in the middle 1950s. There have been many "shipwrecks" along the way. All, in a long list of iatrogenic disasters, reenacted the same depressing scenario. The script was outlined in one ordered pattern of action: an exciting proposal, wide application, belated recognition of the possibility of disastrous complications, and formal evaluation, if it took place at all, long after the unevaluated treatment was in general use.

\section{UNFORGIVING TYRANT}

After basic mechanisms concerning isolated phenomena have been worked out and rigorously battle-tested in preclinical studies, there is an understandable temptation to translate the hardwon information into practical action as soon as possible. But the lesson of history in neonatal medicine is very clear: at every turn, in the search for effective treatments, there are traps to snare the impatient innovator. It has been said that nature is a tyrant queen: make a mistake and she cuts off your head.

In medicine, we are always tempted by the optimistic vision of dramatic therapeutic success. Our daily experience with misery and death makes us desperate to help, but, paradoxically, we need to be preoccupied with the negative aspects of innovation. The reason for this guarded attitude goes back to the fact that our observations about complex events in the natural world are never complete. There are, in fact, no criteria that would even allow us to judge completeness. Nonetheless, doctors, like engineers (and unlike scientists), are obliged to act on the basis of incomplete information about material phenomena. Action in the applied sciences is always an informed compromise. Compared with the small pond of knowledge in medicine, our ignorance is the Atlantic.

\section{ACCEPTING UNCERTAINTY}

The sobering advice about our limitations-that we can only hope to narrow the area of uncertainty - applies with particular force to the field of perinatal/neonatal medicine. Actions here have a greater social and biologic impact on present and future generations than do those in any other sector of medicine. We are the only species on the planet that has ever achieved neonatal survival rates of over $90 \%$. As we strive to improve this record, it is important that we demand an ever higher quality and total amount of evidence before the widespread adoption of new approaches.

\section{TWO IDEOLOGIES}

If such overly cautious advice is followed, it would put a considerable brake on the current rapid pace of change in the medical care of "weaklings." But what is the hurry?

Sackett (18) has recognized that the answer to this question serves to divide our profession into two belief systems: the evangelists and the snails. The advocates of intervention, the evangelists, have impeccable motives. In the face of an ongoing toll of disability and untimely death, they conclude that preexisting evidence, plus common sense, demand action now-even in the absence of field experiments to determine whether alteration of a suspected risk factor will, in fact, alter risk.

The methodologists, on the other hand, are the snails. They are wedded to a series of criteria and strategies that, if vigorously applied, will increase the likelihood that the ultimate conclusion is not too far off the mark. The snails insist that interventions must meet scientific as well as political criteria before they are widely implemented.

\section{IS THERE SOCIETAL CONSENSUS?}

The evangelist faction in neonatal medicine regards recurrent iatrogenic disasters as an inevitable price that must be paid for rapid progress. But, we must ask, does the community at large share medicine's sense of urgency to achieve human perfection in our time? Do those directly affected-parents of very low birth weight and seriously malformed offspring - share medicine's enthusiasm about the unprecedented increase in neonatal survival rates? Is the "body count" a meaningful measure of an advance in the guerrilla war to push back the borderline of viability? Are we to proceed from here as quickly as possible, or as carefully as possible? Shall we follow the evangelists or the snails?

We cannot have it both ways. As the weapons of modern medical warfare increase in effectiveness, there is growing awareness of paradoxical outcomes on the battlefield-they are called disasters of good intent (19).

\section{JANUS-LIKE OUTLOOK OF MEDICINE}

The concerns remind us that medicine, like the Roman god Janus, has two faces. One is preoccupied with the question, "How do we make sense out of information?" Here we have more than 350 years' experience with the approach that Galileo called il cimento, the ordeal. All knowledge claims are subjected to the ordeal of withering criticism by doubting coworkers. The process has been called "organized skepticism;" it is the only way we have of detecting our mistakes and harnessing them for useful purposes. If the claims withstand all of this abuse, they are accepted as temporary but often very useful "working truths." The strength of a claim is measured by the number and the force of attempts to dislodge it.

The second face of medicine looks at the question, "How do we transform new medical information into something of social value?" Here we have little experience because, until recently, interventions were so ineffective that the question was moot. There is growing awareness that claims in this sphere must also run the gauntlet, but there is a crucial difference. Now the relentless criticism must come from skeptics in the community if we are to separate "halfway" technical solutions from solid claims of improvement in the general welfare.

\section{WHO MAKES SOCIAL POLICY?}

The social impact of technologic innovation is now recognized as one of the major issues of our time. It is slowly but surely dawning on the public that unrestrained intensive care of the smallest and the most seriously malformed neonates is unreviewed and unlegislated social policy (20). For example, how much of its resources should the community invest in social interventions to prevent premature birth, and how much in medical rescue in neonatal intensive care (21)? Pregnancy outcome in the United States does not compare favorably with a number of countries with fewer resources. Unlike the United States, these have-less countries have developed provider systems that link prenatal care to comprehensive social and financial benefits that enable pregnant women and new mothers to protect their own health and to nurture their children (22).

It should come as no shock that the community is concerned about the long-term social and biologic consequences of medical actions. And there can be little doubt that neonatal intensive care is social engineering. This never-say-die activity is a form of extremism that resembles eugenics stood on its head; Reverse 
Social Darwinism is a fair label for this completely new idea in the several-million-year existence of the human species. Families and communities need to be thoroughly convinced of the social effectiveness of unbridled medical salvage.

\section{UNEQUAL COMMITMENT}

What happens when the wholehearted dedication of medical personnel to rescue "weaklings" is not matched by an equal commitment on the part of the parents and community? What are the long-term consequences of inequalities in commitment? Parents with marginal financial and emotional resources are often overwhelmed by the survival of a sickly or malformed baby. The situation then becomes a prescription for disaster (23, 24).

The intense efforts in the neonatal period and striking falloff in support when infants leave the hospital were brought to mind forcefully by a particularly gruesome incident that occurred fairly early in the development of the all-out campaign to breach the viability barrier. At the Babies Hospital in New York, we were successful in rearing an 800 -g infant who developed one lifethreatening complication after another. Three months and several tens of thousands of dollars after birth, the baby was sent home to a cold-water flat in upper Manhattan. Within a week we heard that the infant died when a rat chewed off its nose. At that point we remembered the bitter lyrics of Tom Lehrer's song about the folks who build our armed missiles (25): "Once the rockets are up who cares where they come down/"That's not my department,' says Werner von Braun."

\section{MORAL RIGHTEOUSNESS}

The abrupt shift in the care of "weaklings" from moderate means to a kind of technologic exhibitionism has taken on a quasi-religious fervor. The demands have the effect of a divine ordinance: sacrilegious to challenge, impossible to disobey.

Physicians often make the assumption that medical action, especially when it is based on scientifically sound evidence, is a pure, moral, accultural activity. The high aims were put into words by one doctor many years ago when he said, "It is not sufficient that members of the medical profession should set up a standard of morality for themselves, but the people are to be educated up to it" (26). But parents of an extremely premature or malformed child are resentful that they must pass a "sacrifice test" to mitigate the moral expectations of those who do not have to live day by day with the consequences of a diffuse idealism (27). I am reminded here of Diana Vreeland's explanation of her success as a leader in women's fashion: "Given 'em what they don't know they want" (28).

\section{A TIME FOR INTROSPECTION}

What is past is merely prologue. One hundred years after the founding of the American Pediatric Society, we find ourselves about to be launched into uncharted outer space made available by the incredible information explosion in genetics. I cannot think of a better time for introspection. We would do well to consider the biblical injunction to search our souls: Quo vadis? Whither goest thou? A similar question occurred to Captain Ahab during his voyage in relentless pursuit of the great white whale. In a rare moment of insight he confessed, "All my means are sane, my motive and my object are mad."

\section{MODERATION AND COORDINATION}

The exercise of restraint is the most essential secret of humankind's advance. Why, then, has our profession chosen to ignore this vital lesson of history? We need to consider moderating the pace of change. Instead of rapid advances on the basis of uncoordinated knowledge in specialized areas, there might be, as Mumford (29) has advised, a slower but better-coordinated advance that does justice to the processes, functions, and purposes of life. The outcome of interest in all human interventions should be (30): Is life any sweeter? That is the test.

At the hundred-year mark, I suggest that we need to confront T. S. Eliot's question (31), "Where is the wisdom we have lost in knowledge, ... the knowledge we have lost in information?"

\section{REFERENCES}

1. Farber HK, McIntosh R 1966 History of the American Pediatric Society $1887-$ 1956, McGraw-Hill, New York

2. Winslow EEA, Holland DF 1930 Long-time Trends of Mortality Under 1 Year of Age in American Cities; For the Years 1880 Through 1928. Committee Adm Pract, Am Public Health Assn, Washington, DC

3. Cone Jr TE 1979 History of American Pediatrics. Little, Brown, Boston

4. de Mause L (ed) 1974 The History of Childhood. Psychohistory Press, New York

5. Jacobi A 1917 The history of pediatrics in New York. Arch Pediatr 34:1-11

6. Dunham EC 1957 Evolution of premature care. Ann Paediatr Fenn 3:170184

7. Cone Jr TE 1985 History of the Care and Feeding of the Premature Infant. Little, Brown, Boston

8. Silverman WA 1979 Incubator-baby side shows. Pediatrics 64:127-141

9. Budin P 1907 The Nursling. Maloney WJ, translator. Caxton, London

10. Rotch TM 1893 Description of a new incubator. Arch Pediatr 10:661-665

11. Hess JH 1922 Premature and Congenitally Diseased Infants. Lea \& Febiger, Philadelphia

12. Bundesen HN, Dahms OH, Fishbein WI, Harmon GE 1936 Mortality of premature infants. JAMA 107:270-274

13. Wertz RW, Wertz DC 1979 Lying-In: A History of Childbirth in America. Schocken, New York

14. Hess JH, Lundeen EC 1941 The Premature Infant: Its Medical and Nursing Care. Lippincott, Philadelphia

15. Diamond LK 1948 Replacement transfusion as treatment for erythroblastosis fetalis. Pediatrics 2:520-524

16. Silverman WA 1980 Retrolental Fibroplasia: A Modern Parable. Grune \& Stratton, New York

17. Silverman WA 1959 The physical environment and the premature infant. Pediatrics 23:166-171

18. Sackett DL 1975 Controversy in the detection of disease. Lancet 2:357-359

19. Doxiadis S (ed) 1986 Ethical Dilemmas in Health Promotion. Wiley, Chichester

20. Zola IK 1972 Medicine as an institution of social control. Soc Rev 20:487504

21. Institute of Medicine 1985 Preventing Low Birthweight. Natl Acad Press, Washington, DC

22. Guyer B, Wallach LA, Rosen SL 1982 Birthweight standardized neonatal mortality rates and the prevention of low birthweight: how does Massachusetts compare with Sweden? N Engl J Med 306:1230-1233

23. Lasky RE, Tyson JE, Rosenfeld CR, Krasinski D, Dowling S, Gant NF 1987 Disappointing follow-up findings for indigent high-risk newborns. Am J Dis Child 141:100-105

24. Verloove-Vanderhorick SP, van Zeben-van der Aa TM, Verwey RA 1988 Addicted mothers and preterm babies: a disastrous outcome. Lancet 1:421422

25. Lehrer $T 1965$ That Was the Year That Was [Record]. Reprise Records, no. 6179

26. Mohr JC 1978 Abortion in America: The Origin of National Policy. Oxford University Press, New York

27. Stinson R, Stinson P 1983 The Long Dying of Baby Andrew. Little, Brown Boston

28. Vreeland D 1984 DV. Knopf, New York

29. Mumford L 1946 Program for Survival. Harcourt Brace, New York

30. Burroughs J 1900 Indoor Studies. Houghton Mifflin, New York

31. Eliot TS 1963 "The Rock." In: Collected Poems 1909-1962. Harcourt Brace \& World, New York 